\title{
ONCE DAILY IMMEDIATE-AND EXTENDED-RELEASE BILAYER TABLETS OF ETORICOXIB: A STUDY ON THE RELEASE KINETICS
}

\author{
BIBASWAN MISHRA*, BISWARANJAN MOHANTY
}

Department of Pharmaceutics, Institute of Pharmacy and Technology, Salipur, Cuttack 754202, Odisha, India

Email: drbibaswanmishra@gmail.com

Received: 24 Dec 2018, Revised and Accepted: 25 Jul 2019

\begin{abstract}
Objective: In the present work, the main objective was to develop bilayer extended release matrix tablets of etoricoxib by providing a loading dose followed by maintenance dose that expected to improve the therapeutic efficacy of the medication with less toxic effect.

Methods: Bilayer tablets of etoricoxib was developed successfully with the meticulous proportion of release controlling Hydroxy propyl methyl cellulose K100 (HPMC K100) and lactose. The tablets were prepared by wet granulation technique. Granules for immediate layer and extended layer for different formulations were prepared separately. The formulations were developed and evaluations were performed to examine the parameters that affect the in vitro performance of the tablets. The drug-excipient compatibility was ensured by Fourier transform infrared spectroscopy (FTIR) study.

Results: The values of physical parameters of all formulations were found within appreciable limit. Formulation containing HPMC K 100 and lactose in the proportion of $2: 1$ in the extended release layer was able to release $26.22 \%$ of drug in 15 min and shown a steady release of drug for an extended period of $12 \mathrm{~h}$. The dissolution data was put in Korsemeyer-Peppas model in order to find out $\mathrm{n}$ value, which describes the drug release mechanism. The n-value of different formulations were found to be variable. The Fourier transform infrared spectroscopy (FTIR) study revealed absence of any other new peaks and also no differences in the positions of the absorption bands in the bilayer tablet F8 that indicate the lack of significant interactions between etoricoxib and other excipients.
\end{abstract}

Conclusion: It had been concluded that once daily immediate-and extended release bilayer tablet of etoricoxib can be formulated with profound physical characteristics and dissolution properties. This resulted in reducing the daily dose and thus minimise the cardiovascular toxicity of etoricoxib.

Keywords: Etoricoxib, Bilayer technology, Once daily tablet, Release kinetics

(C) 2019 The Authors. Published by Innovare Academic Sciences Pvt Ltd. This is an open access article under the CC BY license (http://creativecommons.org/licenses/by/4.0/) DOI: http://dx.doi.org/10.22159/ijap.2019v11i5.31638

\section{INTRODUCTION}

Etoricoxib; (5-chloro-2-[6-methyl pyridin-3-yl]-3-[4-methyl sulfonyl phenyl] pyridine) is a selective second generation cyclooxygenase-2 inhibitor administered orally as an analgesic and anti-inflammatory drug $[1,2]$. However, the drug possesses a saturation solubility of $78.48 \pm 1.47$ $\mu \mathrm{g} / \mathrm{ml}$. This leads to formulation problems and limit its therapeutic efficacy by delaying the rate of absorption and the onset of action [3].

The recommended dose for etoricoxib is between 60 and 120 $\mathrm{mg} /$ day. It has an estimated $\log \mathrm{P}$ of 3.14 and pKa of 4.6. Pharmacokinetic studies reveal that despite of a potent drug for osteoarthritis, it suffers from severe cardiovascular toxicity issues. The cardiovascular risks of etoricoxib may increase with dose and duration of exposure. Therefore the possible lowest effective daily dose should be developed to combat this problem [4].

Recently, multilayer tablets have been gaining importance for enhancing the formulation efficacy and improving the patient compliance by reducing the dosing burden $[5,6]$. Moreover, the release profiles can be modified using multiple compatible components in the multilayer tablet strategy [7, 8]. In bilayer tablet technology, one is for immediate-release layer and the other is for modified-release layer. The immediate-release layer will disintegrate rapidly and transiently after oral administration, thus providing enough drug for immediate onset of action while, on the other hand, the modified-release part will dissolve slowly in the gastrointestinal tract to maintain a steady drug release.

The rationality of the present study was to explore the feasibility of developing a bilayer tablet strategy, a once daily immediate-and extended-release formulation of etoricoxib. The fast release of drug from the immediate release layer achieve the quick onset and the extended release of drug capable of maintaining the therapeutic level. This resulted in reducing the daily dose and thus minimise the cardiovascular toxicity of etoricoxib. In this study the formulations were developed, and evaluations were performed to examine the parameters that affect the in vitro performance of the tablets.
A novel once daily immediate-and extended-release drug delivery system of etoricoxib was developed for the following reasons: 1) To synchronize drug delivery to achieve quick onset of action in severe pain; 2) To prolong therapeutic effect by continuously releasing the medication over an extended period of time after administration of a single dose; 3) To minimize the frequency of drug administration by developing a once daily therapy; 4) Improved therapy can be provided as the drug exerts its action at a time when it is needed most and dose related side effects could be minimized; 5) Patient convenience and compliance could be achieved.

\section{MATERIALS AND METHODS}

\section{Materials}

Drug etoricoxib was obtained as a gift sample from Hetero drugs, Baddi, India. HPMC K 100 M, HPMC E5 and croscarmellose sodium were procured from Colorcon Asia Pvt. Ltd., Goa, India. Microcrystalline Cellulose, Lactose, starch, Talc and magnesium stearate were purchased from Loba Chemie Pvt. Ltd., Mumbai, India. Poly Vinyl Pyrollidone was bought from SD Fine Chem Limited, Mumbai, India. The materials that were of AR/IR grade and were used as supplied by the manufacturer without further purification or investigation.

\section{Methods}

Preparation of bilayer tablet

The tablets were prepared by wet granulation technique. Granules for immediate layer and extended layer for different formulations were prepared separately. The composition of two layers of tablets are depicted in table 1 [9].

\section{Extended release layer of etoricoxib}

The granules of the extended release layer were prepared by the wet granulation method. After being grinded and sifted through sieve no 60 , the drug was mixed thoroughly with other inactive ingredients excluding talc and subsequently passed through a 16-mesh screen to 
blend the ingredients uniformly. The mixture was granulated using $3 \%(\mathrm{w} / \mathrm{w})$ PVP in a $90 \%$ ethanol solution as binder and then pressed through a 20-mesh screen to prepare wet granulates. After drying at $45^{\circ} \mathrm{C}$ for $1 \mathrm{~h}$ in an oven, the granules were sieved through an16mesh screen and then mixed with talc for the following table ting process.

\section{Immediate release layer of etoricoxib}

The granules of the immediate release layer containing etoricoxib and other excipients (table 1) were fabricated by a similar procedure described above. The superdisintegrant and talc of specified amount were added after granulation.

\section{Preparation of bilayer matrix tablets}

The bilayer tablets were fabricated with a single-punch tablet machine (Cadmach-Ahmedabad) via a single compaction method. Briefly, the weighed granules were sequentially fed manually into the die cavity and then compressed into tablets under pressure between 3 and 15 $\mathrm{kg} / \mathrm{cm}^{2}$. Table 1 exhibits the detailed formula compositions for the bilayer tablets. The size batch was 100 tablets for each formulation.

Table 1 Formulation composition for bilayer tablet

\begin{tabular}{|c|c|c|c|c|c|c|c|c|c|c|}
\hline \multirow[t]{2}{*}{ Excipients } & \multicolumn{10}{|c|}{ Formulations } \\
\hline & F1 & F2 & F3 & F4 & F5 & F6 & F7 & F8 & F9 & F10 \\
\hline \multicolumn{11}{|l|}{ Extended release layer } \\
\hline Etoricoxib (mg) & 60 & 60 & 60 & 60 & 60 & 60 & 60 & 60 & 60 & 60 \\
\hline HPMC K100 (mg) & 60 & 60 & 60 & 60 & 45 & 45 & 60 & 60 & 30 & 30 \\
\hline Lactose (mg) & - & - & - & - & 45 & 45 & 30 & 30 & 60 & 60 \\
\hline PVP (\%) & 3 & 3 & 3 & 3 & 3 & 3 & 3 & 3 & 3 & 3 \\
\hline Talc (\%) & 0.5 & 0.5 & 0.5 & 0.5 & 0.5 & 0.5 & 0.5 & 0.5 & 0.5 & 0.5 \\
\hline \multicolumn{11}{|l|}{ Immediate release layer } \\
\hline Etoricoxib (mg) & 30 & 30 & 30 & 30 & 30 & 30 & 30 & 30 & 30 & 30 \\
\hline HPMC E5 & 30 & - & - & - & - & - & - & - & - & - \\
\hline Lactose (mg) & - & - & 30 & - & 30 & 30 & 30 & 30 & 30 & 30 \\
\hline MCC (mg) & - & 30 & - & - & - & - & - & - & - & - \\
\hline Starch (mg) & - & - & - & 30 & - & - & - & - & - & - \\
\hline Croscarmellose Sodium (\%) & 3 & 3 & 3 & 3 & 3 & 4 & 3 & 4 & 3 & 4 \\
\hline PVP $(\%)$ & 1.5 & 1.5 & 1.5 & 1.5 & 1.5 & 1.5 & 1.5 & 1.5 & 1.5 & 1.5 \\
\hline Talc (\%) & 0.5 & 0.5 & 0.5 & 0.5 & 0.5 & 0.5 & 0.5 & 0.5 & 0.5 & 0.5 \\
\hline
\end{tabular}

${ }^{*}$ PVP-poly vinyl pyrollidone; HPMC-Hydroxy propyl methyl cellulose; MCC-micro crystalline cellulose

\section{Evaluation of etoricoxib bilayer tablet}

\section{Flow property of granules}

The flow characteristics of the granules of both immediate and extended layer were examined through determining inter particle porosity, Hausner ratio and Carr's index $[10,11]$. All the determinations were done in triplicate and the mean values were reported.

\section{Physical parameters of bilayer tablets}

Weight variation, thickness and diameter uniformity, hardness and friability of different batches of bilayer tablets were performed. Twenty tablets were selected randomly from the lot and weighed individually by using digital balance and the weight variation of individual tablet from its mean value was calculated. The thickness and diameter of the tablets in mm was measured by vernier calliper scale. The hardness of the tablets $\left(\mathrm{kg} / \mathrm{cm}^{2}\right)$ was determined in triplicate using Monsanto Hardness Tester [12]. The friability of tablets was determined using Roche Friabilator. It is expressed in percentage $(\%)$. Twenty tablets were initially weighed $\left(\mathrm{W}_{0}\right)$ and transferred into friabilator. The friabilator was operated at $25 \mathrm{rpm}$ for 4 min or run up to 100 revolutions. The final weight of the tablet $\left(\mathrm{W}_{\mathrm{t}}\right)$ was measured. The $\%$ friability was calculated by,

$$
\mathrm{F}=\left[1-\frac{\mathrm{W}_{\mathrm{t}}}{\mathrm{W}_{0}}\right] \mathrm{X} 100
$$

\section{Content uniformity}

Three tablets were selected randomly from each batch and triturate by mortar and pestle. The powder equivalent to $100 \mathrm{mg}$ of etoricoxib was taken into three different $100 \mathrm{ml}$ volumetric flasks. To each of it, $100 \mathrm{ml}$ of ethanol was poured, sonicated for $10 \mathrm{~min}$ and kept for 24 $\mathrm{h}$ away from light. The solutions were filtered through whattman filter paper and the filtrate was analysed in UV-Visible spectrophotometer at $282 \mathrm{~nm}$. The unknown concentration of the drug was determined using standard calibration curve.

\section{In vitro drug release study}

The release of etoricoxib from different formulations was monitored using standard USP dissolution apparatus No. 2 (Paddle method).
Three tablets from each formula were individually tested. The dissolution was performed in $900 \mathrm{ml}$ of Phosphate buffer $\mathrm{pH} 7.4$ for 12 hour. The stirring rate was $50 \mathrm{rpm} \pm 1$ and the temperature was maintained at $37 \pm 0.5{ }^{\circ} \mathrm{C}$. Aliquots of $5 \mathrm{ml}$ were withdrawn manually at predetermined time points till $12 \mathrm{~h}$ and replaced with same quantity of fresh preheated (at $37^{\circ} \mathrm{C}$ ) dissolution medium. Samples were measured spectrophotometrically at $\lambda=282 \mathrm{~nm}$. The amount released was calculated from the regression line of the standard calibration curve developed in the same medium $[13,14]$.

\section{Kinetics of drug release}

To analyze the drug release rate kinetics and mechanism of drug release from the bilayer tablets, the in vitro dissolution studies data was fitted into Zero order, First order, Higuchi, Hixon crowell and Korsmeyer Peppas models. Co-relation coefficient $\left(\mathrm{R}^{2}\right)$ value were the determinant for the best-fit of the model [11].

\section{FTIR-ATR spectroscopy}

FTIR spectra were recorded at room temperature in the mid-IR range (500-4000 $\mathrm{cm}^{-1}$ ) on a Bruker Alfa FTIR spectrometer equipped with a Bruker ZnSe ATR accessory with a single reflection ZnSe crystal. Each spectrum was averaged over 24 scans with a resolution of $4 \mathrm{~cm}^{-1}$. A background scan was recorded prior to the measurement and subtracted from the sample spectra. For each sample, the initial aqueous solution was placed directly on the ATR $\mathrm{ZnSe}$ and the spectrum recorded. The ATR correction to each spectrum was applied using the OPUS software. The spectra were normalized to the same area and compared to each other. To get some insights into the conformational differences of the investigated samples, some spectral ranges were analyzed.

\section{RESULTS AND DISCUSSION}

Evaluation of immediate and extended layer granules

Flow properties of immediate release layer granules and extended release layer granules

The immediate layer granules and extended layer granules of all formulations were determined and the results were depicted in table 2 . The result of flow property study revealed that the granules 
have good flowability against the flowability of drug that ensure the uniform flow of the granule from hopper to the die cavity as a result of reduced cohesiveness. Result of all the flow parameters were obtained within the permissible limit [15].

Table 2 Flow properties of immediate and extended release layer granules

\begin{tabular}{|c|c|c|c|c|c|c|c|c|c|c|}
\hline \multirow[t]{3}{*}{ Formulation } & $\begin{array}{l}\text { Bulk } \\
\text { density } \\
(\mathrm{g} / \mathrm{ml})\end{array}$ & $\begin{array}{l}\text { Tapped } \\
\text { density } \\
(\mathrm{g} / \mathrm{ml})\end{array}$ & $\begin{array}{l}\text { Inter } \\
\text { particle } \\
\text { porosity }\end{array}$ & $\begin{array}{l}\text { Hausner's } \\
\text { ratio }\end{array}$ & $\begin{array}{l}\text { Carr's } \\
\text { index } \\
(\%)\end{array}$ & $\begin{array}{l}\text { Bulk } \\
\text { density } \\
(\mathrm{g} / \mathrm{ml})\end{array}$ & $\begin{array}{l}\text { Tapped } \\
\text { density } \\
(\mathrm{g} / \mathrm{ml})\end{array}$ & $\begin{array}{l}\text { Inter } \\
\text { particle } \\
\text { porosity }\end{array}$ & $\begin{array}{l}\text { Hausner's } \\
\text { ratio }\end{array}$ & $\begin{array}{l}\text { Carr's } \\
\text { index } \\
(\%)\end{array}$ \\
\hline & \multicolumn{5}{|c|}{ Extended Release Layer (Limit) } & \multicolumn{5}{|c|}{ Immediate release layer (Limit) } \\
\hline & $0-1$ & $0-1$ & $0-1.2$ & $<1.2$ & $<40$ & $0-1$ & $0-1$ & $0-1.2$ & $<1.2$ & $<40$ \\
\hline Drug & 0.232 & 0.370 & 1.608 & 1.595 & 37.297 & - & - & - & - & - \\
\hline F1 & 0.469 & 0.518 & 0.202 & 1.104 & 9.459 & 0.453 & 0.519 & 0.281 & 1.146 & 12.717 \\
\hline $\mathrm{F} 2$ & 0.469 & 0.518 & 0.202 & 1.104 & 9.459 & 0.458 & 0.520 & 0.260 & 1.135 & 11.923 \\
\hline F3 & 0.469 & 0.518 & 0.202 & 1.104 & 9.459 & 0.576 & 0.611 & 0.099 & 1.061 & 5.728 \\
\hline $\mathrm{F} 4$ & 0.469 & 0.518 & 0.202 & 1.104 & 9.459 & 0.764 & 0.891 & 0.187 & 1.166 & 14.254 \\
\hline F5 & 0.972 & 1.137 & 0.149 & 1.170 & 14.512 & 0.627 & 0.683 & 0.131 & 1.089 & 8.199 \\
\hline F6 & 0.972 & 1.137 & 0.149 & 1.170 & 14.512 & 0.638 & 0.721 & 0.180 & 1.130 & 11.512 \\
\hline F7 & 0.472 & 0.507 & 0.146 & 1.074 & 6.903 & 0.627 & 0.683 & 0.131 & 1.089 & 8.199 \\
\hline F8 & 0.472 & 0.507 & 0.146 & 1.074 & 6.903 & 0.638 & 0.721 & 0.180 & 1.130 & 11.512 \\
\hline F9 & 0.732 & 0.807 & 0.127 & 1.102 & 9.294 & 0.627 & 0.683 & 0.131 & 1.089 & 8.199 \\
\hline F10 & 0.732 & 0.807 & 0.127 & 1.102 & 9.294 & 0.638 & 0.721 & 0.180 & 1.130 & 11.512 \\
\hline
\end{tabular}

$\mathrm{n}=3$, All determinations were done in triplicate and the mean values are reported.

\section{Evaluation of immediate and extended release bilayer tablets}

The physical parameters for all the formulations is shown in table 3. All the tablets passed weight variation test as the average $\%$ weight variation were within the pharmacopoeia limits of $\pm 7.5 \%$. Tablet mean thickness $(\mathrm{n}=5)$ were almost uniform in all the formulations and values ranged from $3.5 \pm 0.03$ to $4.5 \pm 0.06$. Tablet mean diameter $(n=5)$ were also found to be uniform all the ten formulations i.e. 7.9 $\mathrm{mm}$. The standard deviation values indicated that all the formulations were within the range [9].

Table 3: Evaluation of bilayer tablet formulations

\begin{tabular}{|c|c|c|c|c|c|c|c|c|c|c|}
\hline Formulation & F1 & F2 & F3 & F4 & F5 & F6 & F7 & F8 & F9 & F10 \\
\hline Average weight (mg) & 182 & 180 & 182 & 182 & 252 & 258 & 253 & 261 & 254 & 259 \\
\hline Weight variation (\%) & \pm 1.56 & \pm 1.39 & \pm 2.07 & \pm 1.91 & \pm 2.30 & \pm 2.27 & \pm 2.01 & \pm 2.15 & \pm 2.03 & \pm 2.21 \\
\hline \multirow[t]{2}{*}{ Thickness $(\mathrm{mm})^{*}$} & 3.7 & 3.5 & 3.5 & 3.6 & 4.2 & 4.3 & 4.3 & 4.3 & 4.3 & 4.5 \\
\hline & \pm 0.03 & \pm 0.06 & \pm 0.03 & \pm 0.06 & \pm 0.03 & \pm 0.06 & \pm 0.03 & \pm 0.06 & \pm 0.03 & \pm 0.03 \\
\hline Hardness $\left(\mathrm{kg} / \mathrm{cm}^{2}\right) \#$ & 7.0 & 6.1 & 6.0 & 6.2 & 5.1 & 4.7 & 6.1 & 5.4 & 6.0 & 6.1 \\
\hline Friability (\%) & 0.187 & 0.243 & 0.142 & 0.174 & 0.183 & 0.119 & 0.324 & 0.286 & 0.232 & 0.327 \\
\hline \multirow[t]{2}{*}{ Drug content $(\%)$} & 98.86 & 99.45 & 100.05 & 99.39 & 100.01 & 99.78 & 98.97 & 99.93 & 99.65 & 99.09 \\
\hline & \pm 1.84 & \pm 1.23 & \pm 1.39 & \pm 1.90 & \pm 1.09 & \pm 2.03 & \pm 1.53 & \pm 1.41 & \pm 1.19 & \pm 1.27 \\
\hline
\end{tabular}

All the values are expressed as mean $\pm \mathrm{SD}$, where ${ }^{*} \mathrm{n}=5$ and $\# \mathrm{n}=3$

The mean hardness values $(n=3)$ were measured for all the formulations using a Monsanto hardness tester. The results are tabulated in table 3 . The hardness values ranged from 4.7 to 7.0 $\mathrm{kg} / \mathrm{cm}^{2}$. The values of friability test were given in table 3 . The percent friability for all the formulations was below 1\%, indicating that the friability is within the prescribed limits. The results of friability test indicate that the tablets possess good mechanical strength [16].

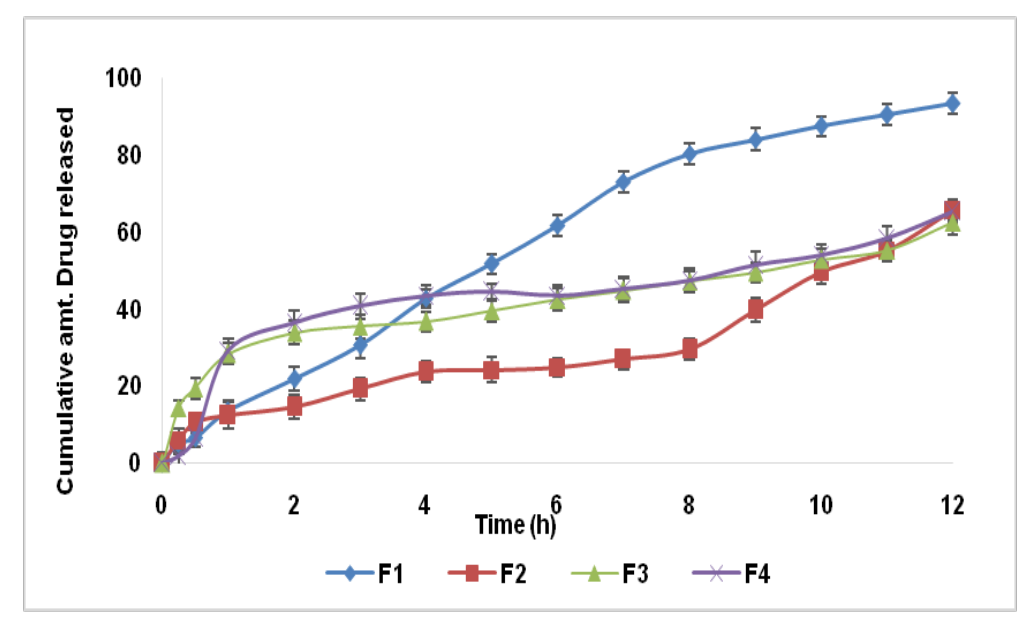

Fig. 1: Comparative $n$ in vitro dissolution profile of F1, F2, F3 and F4 


\section{Content uniformity}

The percent drug content value of etoricoxib was within $98.86 \pm 1.84$ to $100.05 \pm 1.39$. The results within range indicate uniformity of mixing.

\section{In vitro drug release study}

The comparative dissolution profile of F1 to F4 and F5 to F10 are depicted in fig. 1 and fig. 2 respectively. In the formulation F1 to F4 it was observed that for the formulation containing lactose had shown a steady release rate profile as compared to formulation containing HPMC E5, Micro crystalline cellulose and starch. From formulation F1, F2 and F3 the drug was released in a slower rate not able to get a dissolution of $30 \%$ even in the first hour. It is due to the binding ability of HPMC E5, Micro crystalline cellulose and starch that retard the drug dissolution.
From F5 to F10 the extended layer contains HPMC K100 with different proportion of lactose whereas the immediate layer contains only lactose. Cross carmelose sodium was used as superdisintegrant in the immediate layer. It was observed from the dissolution profile that more than $30 \%$ of drug released in the first 15 min from F5, F6, F9 and F10. The drug release was successfully extended up to $5 \mathrm{hr}, 6 \mathrm{hr}, 8 \mathrm{hr}$ and $9 \mathrm{hr}$ for F9, F10, F6 and F5 respectively. F7 was able to release $22.59 \%$ of drug in $15 \mathrm{~min}$ and shown a steady release of drug for an extended period of $12 \mathrm{~h}$. Similarly F8 was able to release $26.22 \%$ of drug in $15 \mathrm{~min}$ and shown a steady release of drug for an extended period of $12 \mathrm{~h}$ (fig. 1 and fig. 2). From the above observation we concluded that the drug release from all the formulations were extended for a longer period of time [17].

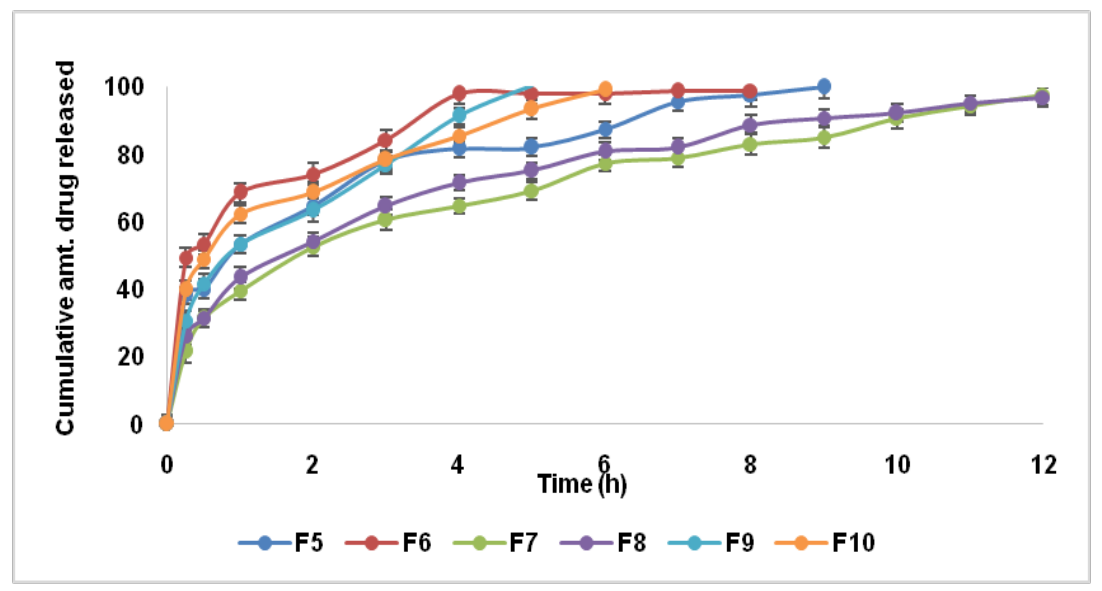

Fig. 2: Comparative in vitro dissolution profile of F5, F6, F7, F8, F9 and F10

From the dissolution profile of all formulation it had been observed that F7 and F8 are suitable for once daily immediate-and extended release bilayer tablet of etoricoxib. In all formulation the rate of release was different due to their differences in composition. The reason behind the variation in drug release kinetics were based upon the nature of ingredients used [10,11].

HPMC K100 had faster drug diffusion from the polymeric matrix with increase in the water uptake. The high water uptake leads to considerable swelling of the polymer matrix that caused the drug to diffuse out from polymer matrix at a faster rate. HPMC K100 had uniform gelling and binding effect because it was easily gelled in presence of aqueous solvent. It plays a significant role in the design of a controlled release product thus it showed better sustained release. The drug diffusion patterns of all the formulations were also depended upon the viscosity of the polymer used. By increasing the viscosity of the system which increased the chances of availability of active binding sites in the polymeric chain [18].

In cross carmelose sodium, the cross-linking reduces water solubility while still allowing the material to swell (like a sponge) and absorb many times its weight in water. As a result, it provides superior drug dissolution and disintegration characteristics, subsequently bringing the active ingredients into better contact with bodily fluids.

Table 4: Various parameters of the model equations of the in vitro release kinetics

\begin{tabular}{|c|c|c|c|c|c|c|c|c|c|c|c|}
\hline \multirow[t]{2}{*}{$\begin{array}{l}\text { Formulation } \\
\text { code }\end{array}$} & \multicolumn{2}{|c|}{ Zero order } & \multicolumn{2}{|c|}{ First order } & \multicolumn{2}{|c|}{ Higuchi model } & \multicolumn{2}{|c|}{$\begin{array}{l}\text { Hixon crowell } \\
\text { model }\end{array}$} & \multicolumn{3}{|c|}{ Korsmeyer-peppas model } \\
\hline & $\mathbf{r}^{2}$ & $\mathbf{K}_{\mathbf{0}}$ & $\mathbf{r}^{2}$ & $\mathbf{K}_{1}$ & $\mathbf{r}^{2}$ & $\mathbf{K}_{\mathbf{H}}$ & $\mathbf{r}^{2}$ & $\mathbf{K}_{\mathrm{HC}}$ & $\mathbf{r}^{2}$ & $\mathbf{K}_{\mathbf{P}}$ & n \\
\hline F1 & 0.9692 & 8.0947 & 0.9776 & 0.0981 & 0.9812 & 29.861 & 0.8883 & 0.226 & 0.9921 & 7.4353 & 1.6299 \\
\hline F2 & 0.9176 & 4.2599 & 0.8441 & 0.0293 & 0.8275 & 14.831 & 0.9527 & 0.1503 & 0.9121 & 8.3483 & 1.0593 \\
\hline F3 & 0.9285 & 3.1586 & 0.9629 & 0.0231 & 0.9727 & 11.852 & 0.8474 & 0.0935 & 0.9754 & 4.0870 & 0.656 \\
\hline F4 & 0.7632 & 3.8296 & 0.855 & 0.0271 & 0.8749 & 15.033 & 0.5695 & 0.1422 & 0.8164 & 8.1433 & 1.4678 \\
\hline F5 & 0.9025 & 6.9481 & 0.803 & 0.2437 & 0.9776 & 25.747 & 0.8543 & 0.134 & 0.9854 & 1.8750 & 0.5797 \\
\hline F6 & 0.9045 & 6.837 & 0.958 & 0.232 & 0.9646 & 23.832 & 0.8837 & 0.1243 & 0.9561 & 1.6018 & 0.4523 \\
\hline F7 & 0.9323 & 5.7498 & 0.9113 & 0.1055 & 0.9874 & 24.104 & 0.8521 & 0.1227 & 0.9911 & 2.6062 & 0.7356 \\
\hline F8 & 0.8946 & 5.6064 & 0.9828 & 0.1072 & 0.9807 & 23.913 & 0.8232 & 0.1161 & 0.9949 & 2.3768 & 0.693 \\
\hline F9 & 0.9763 & 13.946 & 0.8606 & 0.3318 & 0.9909 & 38.746 & 0.9346 & 0.2828 & 0.9903 & 1.9165 & 0.7599 \\
\hline F10 & 0.9451 & 9.5277 & 0.8653 & 0.2604 & 0.9885 & 29.00 & 0.9011 & 0.1824 & 0.9916 & 1.7018 & 0.553 \\
\hline
\end{tabular}

$\mathrm{K}_{0}, \mathrm{~K}_{1}, \mathrm{~K}_{\mathrm{H}}, \mathrm{K}_{\mathrm{HC}}$ are the rate constants for Zero Order, First Order, Higuchi Model, Hixon crowell Model respectively, $\mathrm{r}^{2}=$ correlation co-efficient

Taking different data's from the kinetic profiles, we got different kinetic models belonging to different equations. There was a comparison of all the $\mathrm{R}^{2}$ value of Zero Order, First Order, Higuchi equation and Hixon Crowell equation of F1 to F10 depicted in table 4. From this table we got that in all the formulations the correlation coefficient values were variable. All the formulation followed 
Higuchi model as the $\mathrm{R}^{2}$ value found to be maximum except $\mathrm{F} 2$ and F8. The data obtained was also put in Korsemeyer-Peppas model in order to find out $\mathrm{n}$ value, which describes the drug release mechanism. The n-value of different formulations were found to be variable as depicted in and the drug release mechanism was predicted accordingly table 5 .

Table 5: Release mechanism of drug from different formulation

\begin{tabular}{lll}
\hline Formulation & Diffusion exponent 'n' & Release mechanism \\
\hline F1 & 1.63 & Super case II transport \\
F2 & 1.06 & Super case II transport \\
F3 & 0.66 & Non-Fickian transport \\
F4 & 1.47 & Super case II transport \\
F5 & 0.58 & Non-Fickian transport \\
F6 & 0.45 & Non-Fickian transport \\
F7 & 0.74 & Non-Fickian transport \\
F8 & 0.69 & Non-Fickian transport \\
F9 & 0.76 & Non-Fickian transport \\
F10 & 0.55 & Non-Fickian transport \\
\hline
\end{tabular}

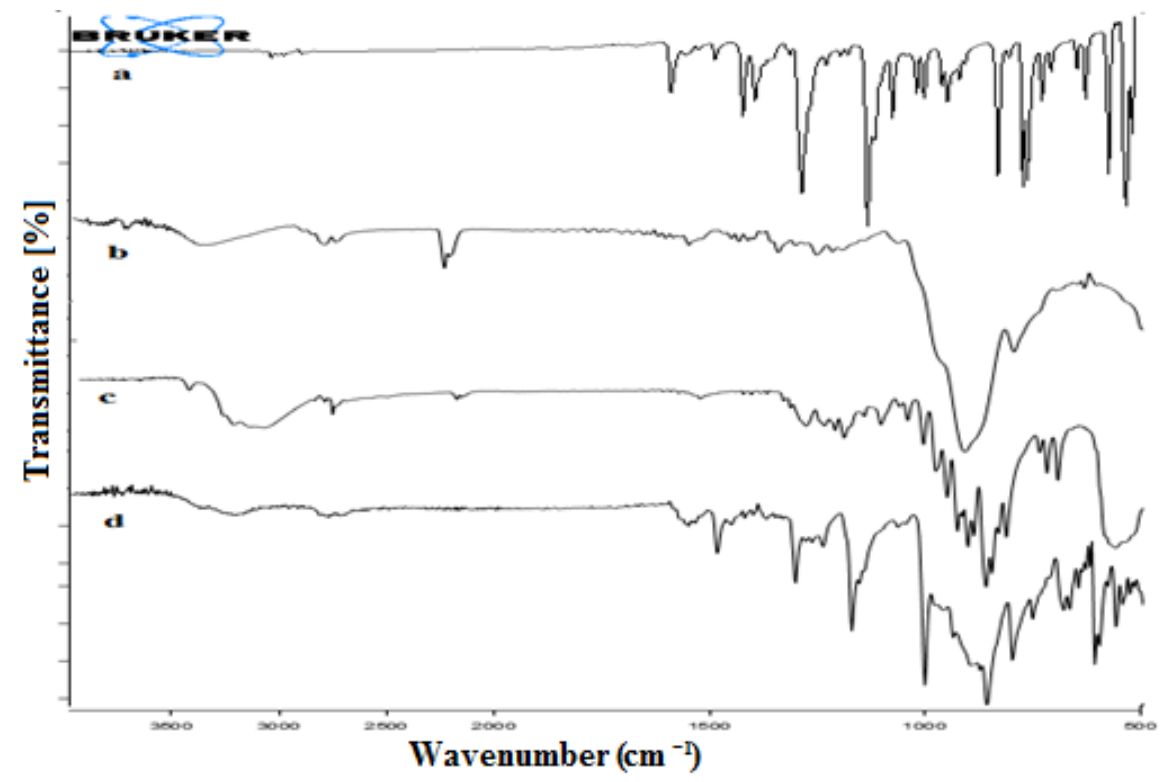

Fig. 3: FTIR study. a) Etoricoxib; b) HPMC K100; c) Lactose; d) F8

\section{FTIR study}

FT-IR studies were done to find out the possible intermolecular interactions between the etoricoxib and other ingredients. The characteristic peaks of etoricoxib, HPMC K100, lactose and F8 are depicted in fig. 3. Absence of any other new peaks and also no differences in the positions of the absorption bands in the bilayer tablet F8 indicate the lack of significant interactions between etoricoxib and other excipients [19].

\section{CONCLUSION}

Bilayer tablets of etoricoxib was developed successfully with meticulous proportion of release controlling HPMC K100 and lactoseThe n-value of different formulations obtained from Korsemeyer-Peppas model were found to be variable. The FTIR study revealed absence of new peaks and also no differences in the positions of the absorption bands in the bilayer tablet F8 that indicate the lack of significant interactions between etoricoxib and other excipients. Hence it had been concluded that F7 and F8 are suitable for once daily immediate-and extended release bilayer tablet of etoricoxib.

\section{AUTHORS CONTRIBUTIONS}

All the author have contributed equally

\section{CONFLICT OF INTERESTS}

The authors have reported no potential conflict of interest in this work

\section{REFERENCES}

1. Agrawal NGB, Porras AG. Dose proportionality of oral etoricoxib, a highly selective cyclooxygenase- 2 inhibitor, in healthy volunteers. J Clin Pharmacol 2001;41:1106-10.

2. Rodrigues AD, Halpin RA, Geer LA. Absorption, metabolism, and excretion of etoricoxib, a potent and selective cyclooxygenase-2 inhibitor, in healthy male volunteers. Drug Metab Dispos 2003;31:224-32.

3. Cochrane DJ, Jarvis B, Keating GM. Etoricoxib. Drugs 2002;62:2637-51.

4. Riendeau D, Percival MD, Brideau C, Charleson S, Dube D, Ethier D, et al. Etoricoxib (MK-0663): preclinical profile and comparison with other agents that selectively inhibit cyclooxygenase-2. J Pharmacol Exp Ther 2001;296:558-66.

5. Goutte F, Guemguem F, Dragan C, Vergnault G, Wehrle P. Power of experimental design studies for the validation of pharmaceutical processes: case study of a multilayer tablet manufacturing process. Drug Dev Ind Pharm 2002;28:841-8.

6. Abebe A, Akseli I, Sprockel O, Kottala N, Cuitino AM. Review of bilayer tablet technology. Int J Pharm 2014;461:549-58.

7. Efentakis M, Naseef $\mathrm{H}$, Vlachou M. Two-and three-layer tablet drug delivery systems for oral sustained release of soluble and poorly soluble drugs. Drug Dev Ind Pharm 2010;36:903-16.

8. Aburahma MH, Yel SH. Novel sustained-release fastdisintegrating multiunit compressed tablets of lornoxicam containing Eudragit RS coated chitosan-alginate beads. Pharm Dev Technol 2011;16:316-30. 
9. Qiang F, Xiaonan S, Yanxian H, Mo L, Jingru L, Jin S, et al. Oncedaily amoxicillin immediate-and extended-release bilayer tablets. Powder Tech 2016;301:405-11.

10. Acharya S, Patra S, Pani NR. Optimization of HPMC and carbopol concentrations in non-effervescent floating tablet through factorial design. Carbohydr Polym 2014;102:360-8.

11. He W, Y Li, R Zhang, Z Wu, L Yin. Gastro floating bilayer tablet for the sustained release of metformin and immediate released of pioglitazone: preparations and in vitro/in vivo evaluations. Int J Pharma 2014;476:223-31.

12. Das MK, Sahu BP, Hazarika JNR. Development of bilayer tablets for immediate and controlled release of allicin. Int J Curr Pharm Res 2017;9:153-60.

13. Mishra B, Sahoo J, Dixit PK. Enhanced bioavailability of cinnarizine nanosuspensions by particle size engineering: optimisation and physicochemical investigations. Mat Sci Eng C 2016;63:62-9.

14. Gerry S. Preformulation predictions from small amounts of compound as an aid to candidate drug selection. In: Mark G.
(Ed). Pharmaceutical preformulation and formulation: a practical guide from candidate drug selection to commercial dosage form: CRC Press Florida USA; 2004. p. 21-2.

15. Kamble S, Poul B, Udapurkar P. Bilayer tablet of tramadol and gabapentin for combination pharmacotherapy of neuropathic pain: development and characterization. Int J Appl Pharm 2018;10:100-7.

16. Roy SK, Naskar S, Kundu S, Koutsu K. Formulation and evaluation of sustained release bilayer tablets of propranolol hydrochloride. Int J Pharm Pharm Sci 2015;7:264-9.

17. Panda N, Reddy AV, Reddy GVS, Sultana A. Formulation design and in vitro evaluation of bilayer sustained release matrix tablets of doxofylline. Int J Pharm Pharm Sci 2015;7:74-83.

18. Parashar T, Singh N. Formulation and in vitro evaluation of bilayer tablet of atenolol for biphasic drug release. Asian J Pharm Clin Res 2018;11:114-9.

19. Mishra B, Sahoo J, Dixit PK. Formulation and process optimization of naproxen nanosuspensions stabilized by hydroxy propyl methyl cellulose. Carbohydr Polym 2015;127:300-8. 